\title{
Case Report: Pulmonary and Liver Sarcoidosis Suspected of
}

\section{Metastasis [version 1; peer review: 1 approved, 1 approved}

\section{with reservations]}

\author{
Behnam Jafari1, Gholamabas Sabz2, Elahe Masnavi (i3), Roghaye Panahi4, \\ Saeid Jokar(i)5, Amrollah Roozbehi (D)6, Sajad Hasanzadeh (iD) 5 \\ ${ }^{1}$ Student Research Committee, Yasuj University of Medical Sciences, Yasouj, Iran \\ 2Department of Obstetrics and Gynecology, Yasuj University of Medical Sciences, Yasouj, Iran \\ ${ }^{3}$ Department of Otolaryngology, Yasuj University of Medical Sciences, Yasouj, Iran \\ ${ }^{4}$ Department of Dental Medicine, Yasuj University of Medical Sciences, Yasouj, Iran \\ ${ }^{5}$ Department of Internal Medicine, Yasuj University of Medical Sciences, Yasouj, Iran \\ ${ }^{6}$ Cellular and Molecular Research Center, Yasuj University of Medical Sciences, Yasouj, Iran
}

V1 First published: 07 Mar 2018, 7:288

https://doi.org/10.12688/f1000research.13787.1

Latest published: 04 Jun 2018, 7:288

https://doi.org/10.12688/f1000research.13787.2

\section{Abstract}

Introduction: Sarcoidosis is a granulomatous disease with unknown cause that can vary from an asymptomatic condition. Almost half of the patients with sarcoidosis have no symptoms. In this article, we describe a sarcoidosis patient with lung and liver engagement; it may be confused with metastasis.

Case report: A 39-year-old man, known as hypothyroidism who had come to the emergency ward with dyspnea and coughing after exposure to detergents in a closed environment A 39-year-old man, known as hypothyroidism who had come to the emergency ward with dyspnea and coughing after exposure to detergents in a closed environment. The patient smoked for 10 years (3 pack/year). No other findings were found in clinical examinations except for wheezing in the right lung. The patient's chest radiography was shown a mass. For further investigation, spiral CT scan was performed. Large lymph nodes on the right side of the trachea, measuring about $23 \mathrm{~mm}$ and a mass of $70 \times 77 \mathrm{~mm}$ in the vicinity of the right lung hilum and a hypodense nodule in the posterior part of the liver with malignancy suspicious were reported. After several biopsy results was shown chronic granulomatous inflammation, the most important differential diagnosis is tuberculosis (TB) and sarcoidosis. Sputum smear, culture, and PCR were performed for tuberculosis. Also, the level of angiotensin-converting enzyme (ACE) was measured for sarcoidosis. the results ruled out TB and shown a higher level of ACE (ACE = 88).After diagnosis treatment started with prednisolone. Now, the patient is in the follow- up.

Conclusion: In hilar lymphadenopathy of lung sarcoidosis is the

\section{Open Peer Review}

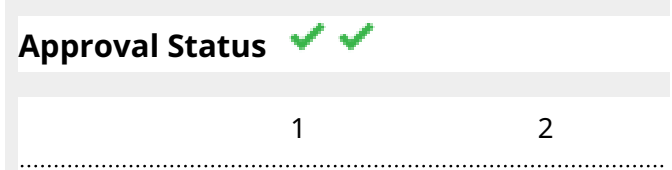

version 2

(revision)

04 Jun 2018

version 1

07 Mar 2018
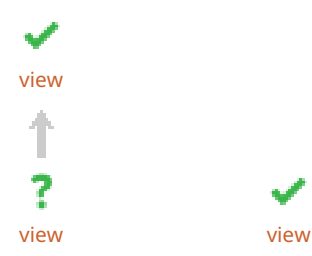

1. Seyed Masoom Masoompour (iD), Shiraz

University of Medical Sciences, Shiraz, Iran

2. Edward S. Chen ID, Johns Hopkins

University, Baltimore, USA

Any reports and responses or comments on the article can be found at the end of the article. 
importance differential diagnosis that should be considered

Keywords

Sarcoidosis, liver, lung, hilar lymphadenopathy

\section{Corresponding author: Sajad Hasanzadeh (hasanzadeh_sajad@yahoo.com)}

Author roles: Jafari B: Conceptualization; Sabz G: Supervision; Masnavi E: Resources, Visualization; Panahi R: Writing - Original Draft Preparation; Jokar S: Writing - Review \& Editing; Roozbehi A: Writing - Original Draft Preparation; Hasanzadeh S: Data Curation, Project Administration

Competing interests: No competing interests were disclosed.

Grant information: The author(s) declared that no grants were involved in supporting this work.

Copyright: $\odot 2018$ Jafari B et al. This is an open access article distributed under the terms of the Creative Commons Attribution License, which permits unrestricted use, distribution, and reproduction in any medium, provided the original work is properly cited.

How to cite this article: Jafari B, Sabz G, Masnavi E et al. Case Report: Pulmonary and Liver Sarcoidosis Suspected of Metastasis [version 1; peer review: 1 approved, 1 approved with reservations] F1000Research 2018, 7:288 https://doi.org/10.12688/f1000research.13787.1

First published: 07 Mar 2018, 7:288 https://doi.org/10.12688/f1000research.13787.1 


\section{Introduction}

Sarcoidosis is a granulomatous disease with unknown cause that can vary from an asymptomatic condition to being lifethreatening ${ }^{1}$. Almost half of the patients with sarcoidosis have no symptoms. In some cases, with the help of chest radiography findings looking for other pathologies, it is diagnosed. Since the lungs are often involved, patients usually come to the clinic with lung complaints (such as shortness of breath, cough) $)^{2,3}$. Some of the clinical manifestations of sarcoidosis have a poor prognosis, including treatment-resistant lung sarcoidosis (pulmonary fibrosis, pulmonary hypertension), cardiac sarcoidosis, neurosarcoidosis, and multiple organ sarcoidosis. These clinical manifestations are often not diagnosed until the end stage of the disease, and their response to treatment is low. The incidence of severe sarcoidosis is the most common cause of death ${ }^{4}$. On time diagnosis, treatment and follow-up of patients reduces mortality. In this article, we describe a sarcoidosis patient with lung and liver involvement, which may be misdiagnosed as cancer metastasis.

\section{Case report}

A 39-year-old man, taxi driver, known to have hypothyroidism (being treated with levothyroxine) presented to the emergency ward with dyspnea and coughing after exposure to detergents in a closed environment. The patient was smoker ( 3 pack/year). The only in clinical examinations except for wheezing in the right side of chest. The patient's chest radiography identified a mass.
For further investigation, a spiral computerized tomography (CT) scan was performed. Lymph nodes were enlarged on the right side of the trachea, measuring about $23 \mathrm{~mm}$ with a mass of $70 \times 77 \mathrm{~mm}$, in the vicinity of the right lung hilum. A hypodense nodule in the posterior part of the liver, suspected to be malignant, was also reported (Figure 1). The lesions were suspected to be metastatic tumors, therefore, a biopsy of the mass was performed via bronchoscopy. The biopsy results were reported as chronic inflammation and mucosal hyperplasia without malignancy, which did not conform to the CT report. The CT has repeated again, and confirmed the previous CT report. A CT guided mass biopsy was performed for pathological evaluation. The result showed chronic granulomatous inflammation, the two most likely causes being tuberculosis (TB) and sarcoidosis. Sputum smear, culture, and PCR were performed to test for TB, and angiotensin-converting enzyme (ACE) levels were measured for sarcoidosis. The results ruled out $\mathrm{TB}$ and showed high levels of ACE $($ ACE $=88$ (normal 8-53)). Two months after the first visit, sarcoidosis was diagnosed and treatment started with prednisolone. Ophthalmology test for eye evaluation, echocardiography for cardiac evaluation and EMG/NCV (Electromyogram test and nerve conduction study) for evaluation of the nervous system were also performed to determine if there was any extra-pulmonary sarcoidosis, however, no lesions were found. After treatment by corticosteroid the symptoms of the patient subsided. Now the patient is on follow-up. Figure 2 show the CT scan of patient after treatment.
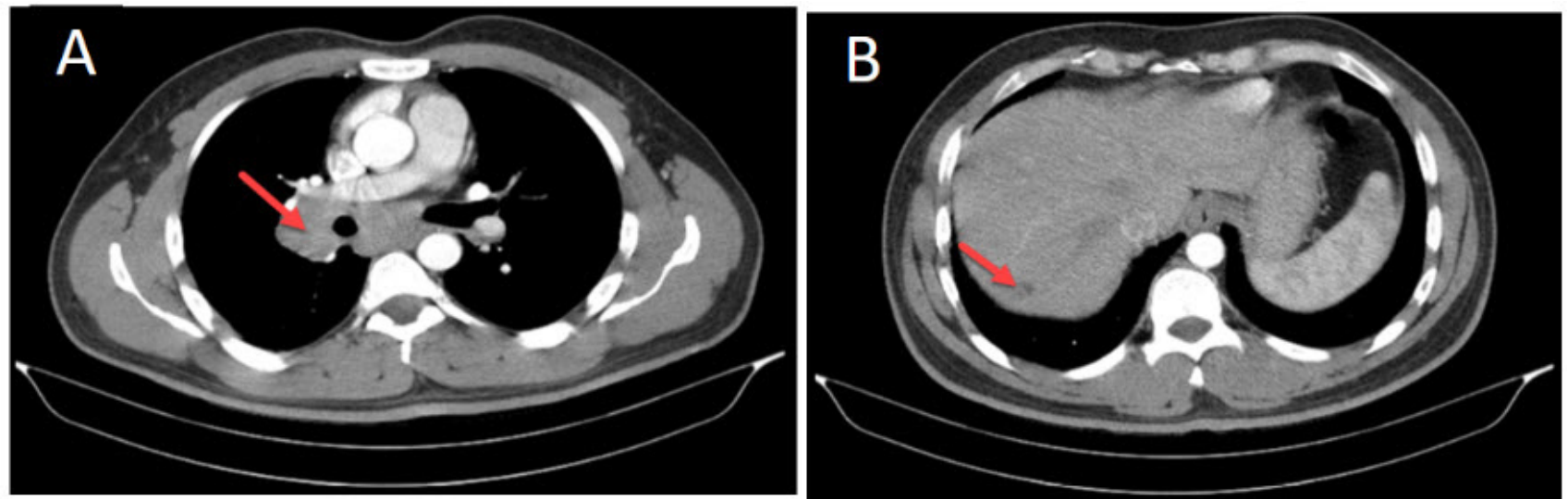

Figure 1. CT scan in-patient with sarcoidosis-(A) Pulmonary lymphadenopathy and (B) granulomatous lesion in Liver involvement. 

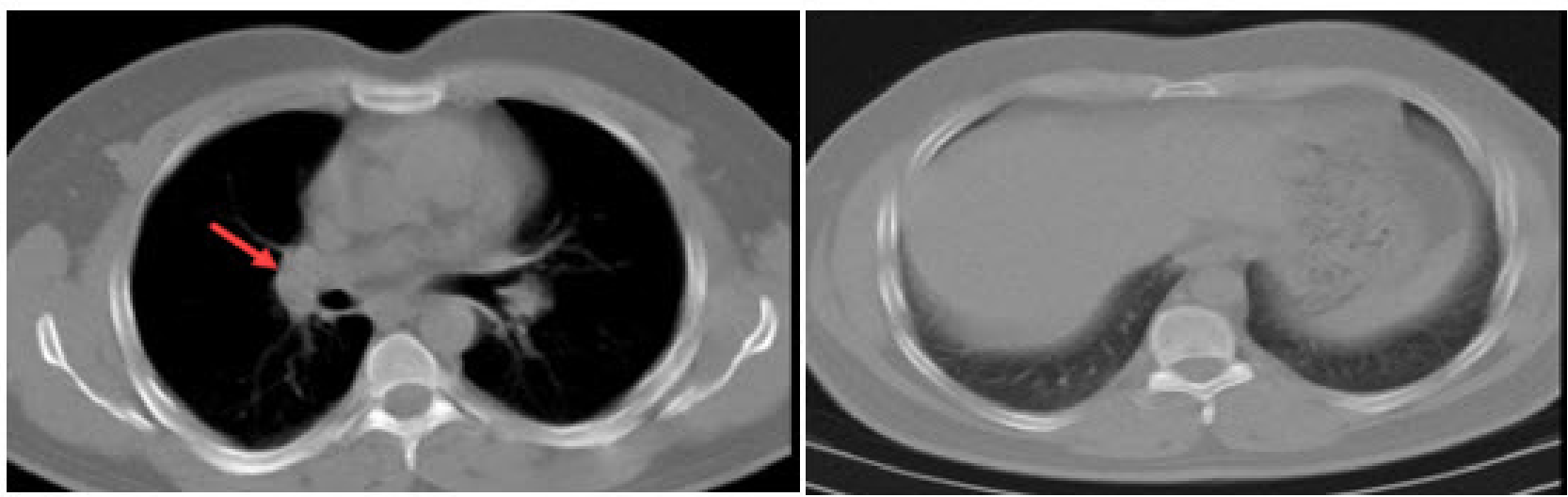

Figure 2. CT scan of patient 6 months after treatment showing decreased size of pulmonary lymphadenopathy and (A) and improvement of hepatic lesions (B).

\section{Discussion}

Sarcoidosis occurs mainly in people aged $20-40$ years and more common in females ${ }^{5}$. Diagnosis is based on medical history, granuloma manifestations in at least two different structures, staining and negative culture for acid-fast bacilli, a lack of occupational and internal exposure to toxins and absence of drugrelated illnesses. It is difficult to determine the prevalence and incidence of sarcoidosis without clinical symptoms. In countries where Mycobacterium tuberculosis is common, sarcoidosis may not be detected ${ }^{5-7}$. The first evaluation of patients suspected of sarcoidosis include; cell blood count, serum biochemistry including creatinine, calcium, liver enzymes, alkaline phosphates, urine analysis, serum protein electrophoresis, inflammatory markers, lactate dehydrogenase, level of enzyme (ACE), and Complete Pulmonary Function Tests that should be performed in patients with respiratory symptoms or abnormalities of the lung parenchyma. In all cases, Mycobacterium and fungal disease should be considered, as it has a similar history (chronic cough) and clinical image (pulmonary lymphadenopathy ${ }^{8}$. A few clinical case report has shown that sarcoidosis is less common in smokers ${ }^{9,10}$. Sarcoidosis has many clinical manifestations and affects all organs of the body. The lung is involved in at least $90 \%$ of sarcoidosis patients. Skin, eyes, liver and peripheral lymph nodes, with a frequency of 10 to $30 \%$ for other involved organs ${ }^{10}$. Cardiac involvement occurs in $25 \%$ of cases, but only causes clinical problems in $5 \%$ of cases, although it may suddenly be fatal, so it is important to examine all patients for cardiac sarcoidosis ${ }^{11,12}$. All patients should also be screened for eye involvement as it can cause visual impairment ${ }^{13}$. Sarcoidosis, like drugs, poisons, viral infections, and flukes induce liver dysfunction ${ }^{14,15}$. Up to $35 \%$ patients have abnormal liver function tests that are not related to the degree of disease ${ }^{16,17}$. Serum levels of ACE are increased in $60 \%$ of patients and have been shown to correlate with the level of disease activity. This test is non-invasive and is highly effective because the enzyme is produced by epithelial granuloma cells and its serum level reflecting the entire granulomatous activity in the body $^{8,18}$. Fatigue was reported in over $50 \%$ of patients, which has a major effect on the quality of life. Pain was reported in $70 \%$ of patients. Arthralgia is the most common type of pain; a headache and chest pain also being reported ${ }^{7,19}$. In terms of treatment, Corticosteroids are a selective therapeutic drug, and methotrexate and hydroxychloroquine are often alternative drugs ${ }^{20-22}$. Our patient had no abnormal blood counts, liver test dysfunction, and non-specific inflammatory markers abnormalities, only an increased titer of ACE with addition liver symptoms that included itching, jaundice, fever and abdominal pain.

\section{Conclusion}

In hilar lymphadenopathy of lung, sarcoidosis is an importance differential diagnosis that should be considered and prior to biopsy of lymph nodes and any invasive procedures, ACE enzyme levels should be measured.

\section{Data availability}

No data is associated with this article.

\section{Consent}

Written informed consent was obtained from the patient for the publication of the patient's clinical details and accompanying images.

\section{Competing interests}

No competing interests were disclosed

\section{Grant information}

The author(s) declared that no grants were involved in supporting this work 
1. Hunninghake GW, Costabel U, Ando M, et al:: ATS/ERS/WASOG statement on sarcoidosis. American Thoracic Society/European Respiratory Society/World Association of Sarcoidosis and other Granulomatous Disorders. Sarcoidosis Vasc Diffuse Lung Dis. 1999; 16(2): 149-73. PubMed Abstract

2. Lynch JP 3rd, Kazerooni EA, Gay SE: Pulmonary sarcoidosis. Clin Chest Med. 1997; 18(4): 755-785

PubMed Abstract | Publisher Full Text

3. Lannuzzi MC, Rybicki BA, Teirstein AS: Sarcoidosis. N Engl J Med. 2007; 357(21) 2153-2165.

PubMed Abstract | Publisher Full Text

4. Swigris JJ, Olson AL, Huie TJ, et al:: Sarcoidosis-related mortality in the United States from 1988 to 2007. Am J Respir Crit Care Med. 2011; 183(11): 1524-30. PubMed Abstract | Publisher Full Text | Free Full Text

5. Newman LS, Rose CS, Bresnitz EA, et al:: A case control etiologic study of sarcoidosis: environmental and occupational risk factors. Am J Respir Crit Care Med. 2004; 170(12): 1324-30.

PubMed Abstract | Publisher Full Text

6. Douglas JG, Middleton WG, Gaddie J, et al:: Sarcoidosis: a disorder commoner in non-smokers? Thorax. 1986; 41(10): 787-91. in non-smokers? Thorax. 1986; 41(10): 787-91.
PubMed Abstract | Publisher Full Text | Free Full Text

7. de Kleijn WP, De Vries J, Lower EE, et al:: Fatigue in sarcoidosis: a systematic review. Curr Opin Pulm Med. 2009; 15(5): 499-506.

PubMed Abstract | Publisher Full Text

8. Lieberman J: Elevation of serum angiotensin-converting-enzyme (ACE) level in sarcoidosis. Am J Med. 1975; 59(3): 365-72. PubMed Abstract | Publisher Full Text

9. Rybicki BA, Major M, Popovich J Jr, et al.: Racial differences in sarcoidosis incidence: A 5-year study in a health maintenance organization. $\mathrm{Am} \mathrm{J}$ Epidemiol. 1997; 145(3): 234-41.

PubMed Abstract | Publisher Full Text

10. Chen ES, Moller DR: Etiology of sarcoidosis. Clin Chest Med. 2008; 29(3): 365-77, vii.

PubMed Abstract | Publisher Full Text

11. Sharma OP, Maheshwari A, Thaker K: Myocardial sarcoidosis. Chest. 1993; 103(1): 253-258.

PubMed Abstract | Publisher Full Text

12. Silverman KJ, Hutchins GM, Bulkley BH: Cardiac sarcoid: a clinicopathologic study of 84 unselected patients with systemic sarcoidosis. Circulation. 1978; 58(6): 1204-1211.

PubMed Abstract | Publisher Full Text

13. Baughman RP, Lower EE, Kaufman AH: Ocular sarcoidosis. Semin Respir Crit Care Med. 2010; 31(4): 452-462.

PubMed Abstract | Publisher Full Text

14. Ghadei R, Eilami O, Jahanbin S, et al:: A Case Report: Liver Abscess Caused by Fasciola hepatica in Yasuj. Armaghane danesh. 2017; 21(10): 1022-8. Reference Source

15. Kasper D, Fauci A, Hauser S, et al:: Harrison's principles of internal medicine. 19e. USA2015. 2015; 2719-2726. Reference Source

16. Nolan JP, Klatskin G: The Fever of Sarcoidosis. Ann Intern Med. 1964; 61(3): 455-61.

PubMed Abstract | Publisher Full Text

17. Kennedy PT, Zakaria N, Modawi SB, et al: Natural history of hepatic sarcoidosis and its response to treatment. Eur J Gastroenterol Hepatol. 2006; 18(7): 721-6. PubMed Abstract | Publisher Full Text

18. Bajpayee L, Govender P, Berman J, et al.: The Diagnostic Value Of Serum Angiotensin Converting Enzyme In Sarcoidosis: A Systematic Review And Meta-Analysis. In B104. SARCOIDOSIS: CLINICAL STUDIES ON DIAGNOSIS, PROGNOSIS AND THERAPY. American Thoracic Society. 2017; 195: A4760. Reference Source

19. Hoitsma E, De Vries J, van Santen-Hoeufft M, et al:: Impact of pain in a Dutch sarcoidosis patient population. Sarcoidosis Vasc Diffuse Lung Dis. 2003; 20(1): 33-39.

PubMed Abstract

20. Judson MA: An approach to the treatment of pulmonary sarcoidosis with corticosteroids: the six phases of treatment. Chest. 1999; 115(4): 1158-1165. PubMed Abstract | Publisher Full Text

21. Baughman RP, Winget DB, Lower EE: Methotrexate is steroid sparing in acute sarcoidosis: results of a double blind, randomized trial. Sarcoidosis Vasc Diffuse Lung Dis. 2000; 17(1): 60-66.

PubMed Abstract

22. Baughman RP: Therapeutic options for sarcoidosis: new and old. Curr Opin Pulm Med. 2002; 8(5): 464-469.

PubMed Abstract | Publisher Full Text 


\section{Open Peer Review}

\section{Current Peer Review Status:}

\section{Version 1}

Reviewer Report 15 May 2018

https://doi.org/10.5256/f1000research.14986.r33755

(C) 2018 Chen E. This is an open access peer review report distributed under the terms of the Creative Commons Attribution License, which permits unrestricted use, distribution, and reproduction in any medium, provided the original work is properly cited.

\section{Edward S. Chen}

Division of Pulmonary and Critical Care Medicine, Department of Medicine, Johns Hopkins University, Baltimore, MD, USA

The authors present a case of pulmonary sarcoidosis arising in a country where tuberculosis may be more common.

There is an error in the Abstract where a sentence is repeated "A 39-year-old man, known as hypothyroidism who had come to the emergency ward with dyspnea and coughing after exposure to detergents in a closed environment A 39-year-old man, known as hypothyroidism who had come to the emergency ward with dyspnea and coughing after exposure to detergents in a closed environment."

In the abstract, the authors should revise the sentence "A 39-year-old man, known as hypothyroidism..." this probably should be revised to "A 39-year-old man with known hypothyroidism..."

On page 3, please revise the sentence "The incidence of severe sarcoidosis is the most common cause of death."

On page 3, the authors should provide information from the bronchoscopy procedure report as to whether there was airway narrowing visualized during the bronchoscopy. This is of particular interest since the patient's main radiographic abnormality is enlarged thoracic lymph nodes without any notable lung infiltrates (stage I chest $x$-ray).

On Page 4, please consider revising "It is difficult to determine the prevalence and incidence of sarcoidosis without clinical symptoms." Perhaps rephrase to clarify that "It is difficult to determine the prevalence and incidence of sarcoidosis since the number of patients who have sarcoidosis but do not have symptoms is unknown."

Is the background of the case's history and progression described in sufficient detail? 
Yes

Are enough details provided of any physical examination and diagnostic tests, treatment given and outcomes?

Partly

Is sufficient discussion included of the importance of the findings and their relevance to future understanding of disease processes, diagnosis or treatment?

Yes

Is the case presented with sufficient detail to be useful for other practitioners?

Yes

Competing Interests: No competing interests were disclosed.

Reviewer Expertise: Immunology of sarcoidosis

I confirm that I have read this submission and believe that I have an appropriate level of expertise to confirm that it is of an acceptable scientific standard.

Reviewer Report 19 March 2018

https://doi.org/10.5256/f1000research.14986.r31753

(C) 2018 Masoompour S. This is an open access peer review report distributed under the terms of the Creative Commons Attribution License, which permits unrestricted use, distribution, and reproduction in any medium, provided the original work is properly cited.

\section{Seyed Masoom Masoompour}

Non-Communicable Diseases Research Center, Shiraz University of Medical Sciences, Shiraz, Iran

This case study presents a man with cough and dyspnea following exposure with irritant agent. His chest imaging showed a right hilar mass. Although this is not an unusual presentation of sarcoidosis but confirms that not all mass is malignant.

My comments:

1. What do you mean by "The incidence of severe sarcoidosis is the most common cause of death"? As Swigris et al. had published, did you mean "The underlying cause of death in most patients with sarcoidosis was the disease itself."

2. Would you please clarify and rephrase this sentence: "The only in clinical examinations except for wheezing in the right side of chest"

3. The authors please add the bronchoscopic findings; was there any mass or narrowing there.

4. Please add the coronal view of chest CT; considering chest physical finding, wheeze, the 
reader would like to see if there is any narrowing in right main and/or intermediate bronchus.

5. Please add the unit of measurement of ACE level.

6. Please add the histologic slide of biopsy to the manuscript.

Is the background of the case's history and progression described in sufficient detail? Yes

Are enough details provided of any physical examination and diagnostic tests, treatment given and outcomes?

Partly

Is sufficient discussion included of the importance of the findings and their relevance to future understanding of disease processes, diagnosis or treatment?

Yes

Is the case presented with sufficient detail to be useful for other practitioners?

Partly

Competing Interests: No competing interests were disclosed.

I confirm that I have read this submission and believe that I have an appropriate level of expertise to confirm that it is of an acceptable scientific standard, however I have significant reservations, as outlined above.

The benefits of publishing with F1000Research:

- Your article is published within days, with no editorial bias

- You can publish traditional articles, null/negative results, case reports, data notes and more

- The peer review process is transparent and collaborative

- Your article is indexed in PubMed after passing peer review

- Dedicated customer support at every stage

For pre-submission enquiries, contact research@f1000.com

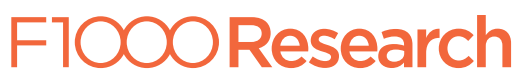

